\title{
A Educação Escolar Quilombola na ANPED: análise da produção do GT 21 - Educação e Relações Étnico-Raciais
}

\author{
José Valdir Jesus de Santana \\ Universidade Estadual do Sudoeste da Bahia \\ Benedito Gonçalves Eugênio \\ Universidade Estadual do Sudoeste da Bahia \\ Nakson Willian Silva Oliveira \\ Universidade Estadual do Sudoeste da Bahia \\ Claudia de Jesus Pereira \\ Universidade Estadual do Sudoeste da Bahia
}

Resumo: A emergência das comunidades negras contemporâneas, rurais e urbanas, que resistiram aos artifícios de apagamento material e simbólico a que foram submetidas ao longo de nossa história, resulta de tensos processos dos quais participa a definição da modalidade de educação escolar quilombola (MIRANDA, 2016). Neste trabalho, analisamos as pesquisas sobre educação escolar quilombola, publicadas pela Associação Nacional de Pós-Graduação e Pesquisa em Educação - ANPED, no Grupo de Trabalho intitulado Educação e Relações Étnico-raciais, no sentido de compreender os modos e formas de apropriação da escola por parte das comunidades remanescentes de quilombos, conforme definido pela Constituição Federal de 1988, o que implica em pensar a relação entre antropologia e educação.

Palavras-chave: Antropologia e educação; Educação escolar quilombola; Quilombos contemporâneos. 


\title{
The Quilombola School Education in ANPED: production analysis of GT 21 - Education and ethnic-racial relations
}

\begin{abstract}
The emergence of contemporary rural and urban black communities, that resisted the artifices of material and symbolic erasure which were subjected over our history, it results of tense processes involving the definition of the mode of quilombola school education (MIRANDA, 2016). In this study, we analyze the research on quilombola school education, published by the National Association of Postgraduate and Research in Education ANPED, in the Working Group entitled Education and Ethnic-racial Relations, in order to understand the ways and means of appropriation of the school By the quilombos' remaining communities, defined by the Federal Constitution of 1988, which implies thinking about the relationship between anthropology and education.
\end{abstract}

Keywords: Anthropology and education; Quilombola school education; Contemporary quilombos.

\section{La Educación Escolar del Quilombo na ANPED: Análisis de la producción do GT 21 - Educación y relaciones étnico-raciales}

Resumen: La emergencia de las comunidades negras contemporáneas, rurales y urbanas, que han resistido a los artificios de borradura material y simbólica que fueron sometidas a lo largo de nuestra historia, resultase de tensos procesos de los cuales participa la definición de la modalidad de educación escolar del Quilombo (MIRANDA, 2016). En este trabajo, analizamos las pesquisas acerca de la educación escolar del Quilombo, publicadas por La Asociación de Pos graduación y Pesquisa en Educación ANPED, en el equipo de trabajo intitulado Educación y relaciones étnico-raciales, en el sentido de comprender los caminos y formas de apropiación de la escuela por parte de las comunidades restantes de quilombos, conforme determinado por la Constitución Federal de 1988, lo que requiere en pensar la relación entre Antropología y Educación.

Palabras clave: Antropología y Educación; Educación Escolar del Quilombo; Quilombos Contemporáneos. 


\title{
Introdução
}

A crescente produção acadêmica voltada para as questões em torno dos quilombos, tanto do passado quanto do presente, avolumam-se, especialmente no campo das ciências sociais e da historiografia, a exemplo dos trabalhos de Reis e Gomes (1996), Almeida (1996, 1999, 2002), Arruti (1997, 2006, 2008), Ratts (2000), Carneiro (1988), Moura (1981, 2001), O’Dwyer (1995, 2007, 2012, 2013), Gusmão (2001, 2007), Figueiredo (2011), Gomes (2015), Nascimento (1980), Nascimento (2008) dentre tantos outros1.

Em fins do século XX, inúmeras comunidades negras rurais passaram a ser identificadas como "remanescentes de quilombos" e, nesse sentido, o ressurgimento da categoria "quilombo" contribuiu para a visibilidade de coletivos negros que, existindo no Brasil sob diversas formas de organização e (auto)denominação, se apropriaram da nominação como estratégia de coletivização da luta política em prol de direitos (ARÊDA-OSHAI, 2016; RATTS, 2000). O termo remanescente de quilombos e sua oficialização pela Constituição Federal de 1988, acabou por produzir um novo "sujeito político" (FIGUEIREDO, 2011) que, juntamente com os movimentos sociais surgidos nas últimas décadas do século passado, a exemplo do Movimento Negro, tem lutado pela construção de políticas públicas voltadas para o acesso à terra, educação e saúde, dentre outras demandas.

Segundo Gomes (2015), o termo quilombo só aparece oficialmente em documentos coloniais no final do século XVII. As comunidades negras, no Brasil, vão se formando em meio à luta e resistência e recebem nomes distintos ao longo de nossa história, variando conforma região. Ademais, para Gomes (2015),

\begin{abstract}
No Brasil, desde as primeiras décadas da colonização, tais comunidades ficaram conhecidas primeiramente com a denominação mocambos e depois quilombos. Eram termos da Africa Central para designar acampamentos improvisados, utilizados para guerras ou mesmo apresamentos de escravizados. No século XVII, a palavra quilombo também era associada aos guerreiros imbangalas (jagas) e seus rituais de iniciação. (GOMES, 2015, p.12).
\end{abstract}

Para Arruti (2008), conforme a legislação colonial, bastava a reunião de cinco escravos fugidos, ocupando ranchos permanentes, para caracterizar a existência de um quilombo. Todavia, para a legislação imperial, bastavam três escravos fugidos, mesmo que não formassem ranchos permanentes e, nesse sentido, afirmar a existência de um quilombo significava apenas identificar um objeto de repressão, sem que isso necessitasse ou implicasse qualquer conhecimento objetivo sobre tal objeto.

Com a instauração da ordem republicana, o termo quilombo não desaparece, mas sofre suas mais radicais ressemantizações, posto que deixa de ser usado pela ordem repressiva para tornar-se metáfora corrente nos discursos políticos, como signo de resistência (ARRUTI, 2008). Em relação a esse processo de ressemantização, Arruti apresenta três formas distintas de como os quilombos passam a ser compreendidos:

\footnotetext{
${ }^{1}$ O livro "Direitos quilombolas \& dever de Estado em 25 anos da Constituição Federal de 1988”, organizado por Osvaldo Martins de Oliveira (2016), publicado pela Associação Brasileira de Antropologia, é uma obra fundamental e atualíssima; apresenta uma diversidade pesquisas, realizada em todas as regiões do país, ao mesmo tempo em que recupera o debate em torno da "questão quilombola", pós Constituição Federal de 1988.
} 


\begin{abstract}
A primeira delas fala do quilombo como "resistência cultural", tendo como tema central a persistência ou produção de uma cultura negra no Brasil. O tema está em pauta desde 1905, quando Nina Rodrigues, pela primeira vez, caracterizou Palmares como uma forma de persistência da África no Brasil. [...] O segundo plano de ressemantização do quilombo passaria pela sua vinculação à resistência política, servindo de modelo para se pensar a relação (potencial) entre classes populares e ordem dominante. Neles a referência à África é substituída pela referência ao Estado ou às estruturas de dominação de classe e o quilombo (em especial Palmares) serve para pensar as formas potencialmente revolucionárias de resistência popular. [...] $\mathrm{O}$ terceiro plano de ressemantização do quilombo é operado pelo movimento negro que, somando a perspectiva cultural ou racial à perspectiva política, elege o quilombo como ícone da "resistência negra". Apesar de ser possível identificar tal apropriação desde a década de 1950, com o jornal negro O Quilombo, de iniciativa de Abdias do Nascimento, ela só se tornaria sistemática ao longo dos anos de 1970, com a redescoberta de Palmares. (ARRUTI, 2008, p. 318-320).
\end{abstract}

Dessa forma, "ainda que tenha um conteúdo histórico, o mesmo vem sendo "ressemantizado" para designar a situação presente dos segmentos negros em diferentes regiões e contextos do Brasil" (O'DWYER, 2007), especialmente com o aprofundamento das discussões em torno das relações raciais no país, a partir da emergência do Movimento Negro Unificado, em fins da década de 1970. É, portanto, no contexto do Movimento Negro, nas últimas décadas do século passado, que a ideia de quilombo ganhou força simbólica e política e, nesse sentido, a construção do "quilombismo" contemporâneo, termo cunhado por Abdias do Nascimento (1980) vai se dando junto à construção da agenda política produzida pelo movimento negro deste país.

Segundo O’Dwyer (2007) o termo "remanescente de quilombo", como tem sido utilizado atualmente, ganha estatuto jurídico a partir da Constituição de 1988, que garantiu a legalização fundiária, através do artigo 68, do Ato das Disposições Constitucionais Transitórias, quando diz: "Aos remanescentes das comunidades de quilombos que estejam ocupando suas terras é reconhecida a propriedade definitiva, devendo o Estado emitir-lhes os títulos respectivos". Nos últimos anos, após Constituição de 1988, o conceito de quilombo tem recebido novas interpretações. De acordo com o Decreto $\mathrm{n}^{0} 4.887 / 2003$ os quilombos são entendidos como:

\footnotetext{
Os grupos-étnico raciais segundo critérios de auto-atribuição, com trajetória histórica própria, dotados de relações territoriais específicas, com presunção de ancestralidade negra relacionada com a resistência à opressão histórica sofrida. (BRASIL, 2003).
}

A partir dessa nova configuração, segundo Arruti (2008), há grandes questionamentos sobre este conceito, ainda em aberto, na disputa pelo seu significado, aspecto também ressaltado por Figueiredo (2011). Nesse sentido, conforme Arruti (2008, p. 316) "o que está em disputa, portanto, não é a existência destas formações sociais, nem mesmo das suas justas demandas, mas a maior ou menor largueza pela qual o conceito as abarcará, ou excluirá completamente”.

Entre final da década de 1990 e primeiros anos do século XXI, aprofundase o movimento em torno das organizações quilombolas que passam a operar em termos de discursos etnopolíticos, multiplicando-se em vários estados da federação. Conforme Domingues e Gomes (2013, p. 15) "ao lado da regularização fundiária, o acesso às políticas públicas - como educação, saúde, saneamento básico e eletrificação - e a garantia dos Direitos Humanos são outras bandeiras do protagonismo quilombola".

O certo é que as comunidades quilombolas ganham cada vez mais importância no cenário nacional - na academia, na imprensa, nas decisões judiciais e no parlamento. No que se refere ao campo da educação, as Diretrizes Curriculares Nacionais para a Educação das Relações Étnico-raciais e para o 
Ensino de História e Cultura Afro-Brasileira e Africana, instituídas em 2004, voltadas para auxiliar na implementação da Lei 10. 639/2003, que instituiu a obrigatoriedade do ensino da História da Cultura Afro-Brasileira em todo o país, ao longo da Educação Básica, e o Estatuto da Igualdade Racial de 2010, preveem ações voltadas a elas. Do mesmo modo, em 2012, são publicadas as Diretrizes Curriculares Nacionais para a Educação Escolar Quilombola, importante marco que vem com o objetivo de assegurar uma educação específica e diferenciada para essas comunidades.

No tópico seguinte, apresentaremos, mesmo que de forma breve, como se constituirão as políticas de educação para comunidades quilombolas em nosso país, além de situar algumas pesquisas que têm sido produzidas em torno na educação escolar em contexto quilombola, na interface entre antropologia e educação. Acreditamos que construir diálogos entre antropologia e educação, como tem proposto Gusmão $(1997,2004)$, Rocha e Tosta (2009) e Tosta e Rocha (2014), parece ser fundamental, posto que isso implica, como propõem Rocha e Tosta (2009, p. 17) em compreender que "a antropologia é uma forma de educação, bem como a educação só é possível como prática antropológica”. Nesses termos, compreender como cada comunidade quilombola tem se apropriado da escola parece ser o grande desafio das pesquisas que estão por ser feitas e isso exige cautela e respeito a essas comunidades, posto que a escola, ao longo do tempo, tem se configurado como o espaço de negação da cultura desses sujeitos e de suas identidades étnico-culturais. Do mesmo modo como existem "políticas culturais para os índios e [...] políticas culturais dos índios”, como propõe Carneiro da Cunha (2014), não seria exagero deslocarmos esta compreensão para os contextos quilombolas; ou seja, se existem políticas culturais para os quilombolas e as de educação escolar estão entre algumas destas políticas, existem, com toda certeza, políticas quilombolas de educação escolar, mesmo quando a escola aparenta não muito diferente das outras escolas consideradas regulares (ou não quilombolas), tendo em vista que, no limite, quem deve definir a escola mais "adequada" para suas comunidades são os quilombolas, seja ela "mais" ou "menos" diferenciada. Daí a necessidade em se compreender cada contexto e, nesse sentido, a etnografia será sempre uma grande aliada. Como já nos disse Sahlins (2004, p. 184) "nenhum objeto, nenhuma coisa existe ou tem movimento numa sociedade humana exceto pela significância que os homens lhe possam atribuir", certamente isso vale também para a escola.

\section{Das políticas de educação escolar para quilombolas: breves considerações}

A obrigatoriedade do ensino da história e cultura africana e afro-brasileira nas escolas do país, em conformidade ao que determina a Lei 10.639/2003, abre um precedente importante para que os processos de ensino aprendizado, no contexto das comunidades remanescentes de quilombo, bem como os modos de fazer e viver dos quilombos contemporâneos, sejam considerados como essencial para a formação de uma nova estrutura de educação no Brasil (PARÉ, OLIVEIRA e VELOSSO, 2007).

A educação escolar para quilombolas se sustenta, no plano normativo, em ao menos quatro documentos, a saber: a Lei Federal $n^{0}$. 10.639/2003 e suas Diretrizes Curriculares de 2004; a Convenção 169 da OIT (Organização Internacional do Trabalho), promulgada pelo decreto 5.051, de 2004, que 
garante o direito de uma educação apropriada às diferenças das populações étnicas; o Plano Nacional de Desenvolvimento de Populações Tradicionais (decreto 6.040, 2007), que aponta para a necessidade de se produzir modalidades de educação adequadas aos modos de vida das populações tradicionais; e a Resolução $\mathrm{n}^{\mathrm{O}} 7$ de 2010 do CNE (Conselho Nacional de Educação), que avança na garantia de uma educação diferenciada, ao mencionar a necessidade de respeito por parte das escolas que atendem às populações do campo, comunidades indígenas e quilombolas, para com suas peculiaridades de modos de vida. Além disso, esta mesma Resolução recomenda a utilização de pedagogias condizentes com as suas formas próprias de produzir conhecimentos (ARRUTI, 2011). Temos, ademais, as Diretrizes Curriculares Nacionais para a Educação Escolar Quilombola, instituídas pela Resolução n ${ }^{\circ} 8$ de 20 de novembro de 2012, o Plano Nacional de implementação das Diretrizes Curriculares Nacionais para a Educação das Relações Étnico-Raciais e para o Ensino de História e Cultura Afro-Brasileira e Africana, de 2013, e o atual Plano Nacional de Educação.

Em relação à categoria escola quilombola, Arruti (2011) faz uma advertência que nos parece importante e que tem, de certa forma, levantado questões, tanto para as comunidades quilombolas, quanto para as Secretarias de Educação, posto que reverbera no modo como as políticas públicas educacionais têm sido construídas para essas comunidades. Nesse sentido, segundo Arruti,

\begin{abstract}
Uma boa ferramenta para nos aproximarmos da categoria "escola quilombola" é o Censo Escolar que, a partir de 2004, passa a contar com um item de diferenciação e identificação destas escolas. É preciso, porém, novamente, fazer esta aproximação com cuidado no uso das categorias. Em primeiro lugar, há a questão das variações derivadas desta classificação ser puramente espacial, já que as escolas situadas dentro do território da comunidade quilombola podem não atender apenas (e eventualmente, nem mesmo principalmente) as crianças desta comunidade, da mesma forma que escolas situadas na vizinhança, mas fora do território comunitário, podem atender massivamente as crianças de uma determinada comunidade. Em segundo lugar, aquilo que genericamente é chamado de "escola quilombola" (inclusive em documentos oficiais) e que, desta forma, nos leva a imaginar uma situação escolar diferenciada, na verdade corresponde ao que no Censo Escolar é identificado, de forma muito mais prosaica, como "escolas localizadas em áreas de remanescentes de quilombos". Ou seja, escolas que são "quilombolas" apenas na medida em que estão sobre terras identificadas (na maioria das vezes muito tempo depois de a escola ter sido criada) como de comunidades remanescentes de quilombos, sem que isso implique a existência de qualquer diferenciação na sua forma física, nos métodos pedagógicos, na sua gestão, na composição e formação dos seus professores ou nos materiais didáticos utilizados. (ARRUTI, 2011, p. 168-169).
\end{abstract}

Temos, portanto, que os projetos de educação e as experiências de educação em contexto quilombola se encontram em construção. Ademais, é preciso refletir acerca do que se coloca como necessidade em termos de educação, para os coletivos remanescentes de quilombo ou, como propõem Arruti (2009), Gusmão e Souza (2012): O que se quer é uma educação nos quilombos ou para os quilombos? Na perspectiva de Gusmão e Souza,

\footnotetext{
A escola que está "nos" quilombos contemporâneos [referindo-se a análises que fizeram de teses e dissertações] não leva em conta as realidades do processo educativo mais amplo, e suas ações se voltam para a reprodução da negação da diferença e da igualdade com base na cultura brancocêntrica, urbana e capitalista. Não se trata da escola pensada "para quilombos", pelos próprios quilombolas, mas de uma instituição construída "para quilombos" no sentido da exclusão, da verticalização das relações de imposição de valores, crenças, formas de aprendizagem e conhecimentos. (GUSMÃO e SOUZA, 2012, p. 227).
}

Nos últimos anos, mesmo que de forma tímida, tem crescido o número de pesquisas que se voltam a analisar aspectos da educação e da educação escolar 
em contexto quilombola, a exemplo dos trabalhos de Ramos (2009), Santos (2010), Souza (2009), Reis (2003), Miranda (2016), Costa, Dias e Santos (2016), Trindade e Aragão (2016), Santos (2015), Purificação (2015), Oliveira (2014), Silva (2014), Fernandes (2013), Onofre (2014), Macedo (2015), Silva (2013) dentre outros. Não temos condições, no limite desse texto, de apresentar aspectos e questões que foram discutidos nesses trabalhos, contudo, alguns dos autores citados serão recuperadas no próximo tópico, em que nos voltaremos à análise da produção da ANPED. Nesta breve apresentação em que buscamos demonstrar como vão se constituindo os quilombos contemporâneos e, do mesmo modo, como está sendo pensada/construída a política de educação escolar para as comunidades remanescentes de quilombo, tínhamos por objetivo situar o leitor, mesmo que minimamente, em relação a essa temática/problemática, posto que o nosso propósito é, sobretudo, apresentar os trabalhos publicados no GT 21 da ANPED, exclusivamente os que tratam da educação escolar quilombola. É disso que trataremos na próxima seção.

\section{Educação escolar quilombola no GT 21- Educação e Relações Étnico-raciais - ANPED}

Como já referido, nesse trabalho, nossa intenção é apresentar a produção teórica/acadêmica em torno da educação escolar quilombola, a partir dos trabalhos que têm sido publicados no GT 21 da Associação Nacional de PósGraduação e Pesquisa em Educação - ANPED. Criado oficialmente na $24^{\mathrm{a}}$ Reunião Anual da Associação, em 20012, com o nome Grupo de Estudos AfroBrasileiros e Educação, a partir de 2009, torna-se Grupo de Trabalho sobre Educação e Relações Étnico-raciais; este GT têm sido um espaço de discussão importante em torno das questões étnico-raciais e de sua articulação com o campo da educação e da educação escolar. Analisamos os trabalhos publicados na forma de comunicação oral entre os anos de 2002 a 20153. Neste período, foram publicados 165 trabalhos na forma de comunicação oral; destes, somente 13 tinham como "objeto" de estudo comunidades quilombolas, sendo que 12 estavam relacionados à educação escolar quilombola.

No ano de 2002, dos três trabalhos publicados no referido GT, nenhum esteve relacionado à educação quilombola; em 2003, ano em que foi promulgada a Lei 10.639/2003, dos 9 trabalhos publicados, nenhum fez referência ou ao menos citou a educação escolar quilombola. Em 2004, dos nove trabalhos publicados, somente 1 faz referência a uma comunidade quilombola de Minhas Gerais, mas não tem como objeto a educação. No ano de 2005, foram publicados 24 trabalhos, não obstante, nenhum desses trataram da educação quilombola. Em 2006, foram publicados 11 trabalhos, mas somente 1 fez relação à educação quilombola. No período de 2007 a 2009 foram publicados 26 trabalhos, mas nenhum voltado à educação escolar quilombola. Em 2010, dos 13 trabalhos publicados, somente 1 versava sobre educação quilombola. Em 2011, dos trinta trabalhos publicados, 4 estavam relacionados à educação quilombola4. No ano de 2012, dos 22 trabalhos publicados, 2 se debruçaram sobre educação escolar quilombola. Em 2013, dos 18 trabalhos, somente 3

\footnotetext{
${ }^{2}$ Criado em 2001, o referido GT só começa a funcionar, recebendo trabalhos no formato de comunicação oral e pôster a partir das reuniões científicas realizadas pela Associação a partir de 2002.

${ }^{3}$ Em 2015 foi realizado o último encontro da Associação; o próximo será realizado em 2017.

${ }^{4}$ Além dos quatro trabalhos referidos, foi publicado o trabalho "O ensinar e o aprender do jongo em comunidades quilombolas: a maestria dos jongueiros Cumba” de autoria de Carolina dos Santos Bezerra Perez. Por ser um trabalho que não trata diretamente da educação escolar quilombola, não o incluímos em nossa análise.
} 
refletiam sobre a temática em questão. Em 2015, dos 29 trabalhos publicados, nenhum estava relacionado à educação escolar quilombola. Passemos à apresentação desses trabalhos.

Marques (2006) realiza um estudo comparativo no município de Campo Grande, MS, entre duas escolas, uma localizada na periferia e outra em uma escola de remanescente de quilombo, tendo como objetivo analisar como professores, de $5^{\mathrm{a}}$ a $8^{\mathrm{a}}$ série, lidavam com a pluralidade cultural (tema transversal) em suas práticas pedagógicas. Conforme Marques (2006), referindo-se à escola localizada na periferia de Campo Grande, "pelas entrevistas e depoimentos constatou-se que os temas transversais são abordados de maneira fragmentada e inconsistente pelos professores da escola, os quais reconhecem a importância deles, mas não realizam um trabalho integrado" (MARQUES, 2006, p 11), sendo abordados, sobretudo, na disciplina de Língua Portuguesa.

Em relação à escola localizada em área de remanescente de quilombo, a autora começa por avaliar o Projeto Político Pedagógico da instituição, afirmando que este necessita de maior fundamento teórico. Ademais, segundo Marques (2006, p. 14), "são desenvolvidos alguns projetos na escola, mas percebe-se que esses trabalhos estão voltados para o social da comunidade e não para o processo ensino-aprendizagem. A discussão em torno da temática Pluralidade Cultural não é a mais relevante para a escola”. Segundo a autora, através das entrevistas realizadas com os professores pode-se constatar que questões relacionadas à Pluralidade Cultural, ao preconceito e discriminação racial são abordadas de forma esporádica, sobretudo nas disciplinas de História e Geografia.

Maroun e Arruti (2010) fazem uma análise antropológica das ressignificações contemporâneas do jongo ou caxambu - nomes pelos quais é conhecida uma dança ritual entre comunidades negras rurais e urbanas do Sudeste do Brasil -, no sentido de compreender sua relação com a educação em duas comunidades remanescentes de quilombo do estado do Rio de Janeiro: Campinho da Independência (Parati) e Bracuhy (Angra dos Reis). No texto, os autores trabalham com três eixos de análise: 1) a ressignificação do jongo enquanto marca identitária na luta política quilombola por reconhecimento; 2) os mediadores fundamentais nesse processo de resgate, perpetuação e ensinoaprendizagem do jongo; 3) o papel que o jongo tem assumido nas discussões sobre uma proposta de educação diferenciada para comunidades quilombolas. Conforme os autores,

\begin{abstract}
A prática do jongo vem sendo ressignificada e recriada pelas comunidades e a principal razão parece ser a mudança das funções sociais atribuídas a ela. Crianças e jovens passam a ser chamados a aprender o jongo, ao contrário do que acontecia no passado, em função dele figurar uma nova forma de suas comunidades afirmarem pertencimentos culturais e identitários. Ao mesmo tempo, o jongo conquista legitimidade pública, tornando-se um importante fator de visibilidade política socialmente positivada destes grupos e elemento importante principalmente no que tange à luta por suas terras. (MAROUN e ARRUTI, 2010, p.4).
\end{abstract}

A comunidade de Bracuhy é reconhecida como uma "comunidade de resistência jongueira”. Segundo os autores, esta categoria nativa está presente nos discursos de lideranças políticas de Campinho da Independência, o que assinala o protagonismo de Bracuhy no processo de resgate do jongo em outras comunidades, a exemplo de Campinhos da Independência, Marambaia e outras. Nesse sentido, a Comunidade Bracuhy

Surge como ponto central de uma rede de resgate do jongo na região sul fluminense, que pode ser compreendida pela proximidade entre as regiões e a consequente 
facilidade de acesso, mas principalmente por todas estas comunidades estarem sujeitas a questões muito parecidas com relação ao preconceito das autoridades locais e à luta pela terra. (MAROUN e ARRUTI, 2010, p.5).

Asseguram os autores (2010, p. 5-6) que foi na década de 90 do século XX que se iniciou uma busca pelo resgate do jongo em algumas comunidades quilombolas, o que trouxe consequências importantes para os dias atuais. "O jongo torna-se um signo, uma marca de pertencimento a uma identidade negra" (MAROUN e ARRUTI, 2010, p. 5). O jongo apresenta-se hoje, portanto, ressignificado e, talvez, a maior marca deste processo de ressignificação seja a visibilidade permitida pelos Encontros Nacionais de Jongueiros.

No que diz respeito à prática do jongo e os processos de educação no contexto dessas duas comunidades, afirmam Moraun e Arruti,

[...] Os processos de ensino-aprendizagem do jongo são realizados em espaços de educação não-formais sem qualquer relação com a educação formal, sendo até mesmo recusados e evitados pela direção e pelos professores das escolas que atendem tais comunidades. Isso torna os Pontos de Cultura espaços de mediação fundamentais, muito valorizados pelas comunidades, também no que tange a educação quilombola, haja vista que subsidiam financeiramente os projetos voltados ao desenvolvimento e perpetuação de saberes tradicionais e culturais, dentre os quais o jongo se destaca. Ao mesmo tempo, essa valorização se expressa pelo desejo das comunidades que não possuem os Pontos em conseguir implementá-los, como é o caso de Bracuhy. São através deles que elas encontram um caminho de diálogo positivo com a esfera pública, assim como experimentam modelos alternativos de uma educação diferenciada envolvida com o projeto político da comunidade. (MAROUN e ARRUTI 2010, p 10).

Segundo os autores, a pesquisa acabou por revelar a distância que a educação escolar possui da cultura local e a ênfase que é dada ao processo de ensino aprendizagem da prática cultural do jongo no contexto de resistência quilombola. "O jongo, portanto, é disseminado em contexto extra-escolar, isto é, os processos educativos referentes a ele tanto em Campinho como em Bracuhy ocorrem por meio da cultura" (MAROUN e ARRUTI, 2010, p.12).

Oliveira (2011) problematiza os limites de uma educação do campo, a partir das demandas trazidas pelo movimento quilombola, posto que, segundo a autora, os discursos em torno da educação do campo acabaram por homogeneizar as chamadas "populações do campo". Ademais, segundo a autora, a produção teórica sobre a educação do campo no Brasil ainda é um território dominado pela discussão camponesa e de classe. Oliveira (2011) recupera as lutas do campesinato no Brasil, a partir da emergência dos denominados "novos movimentos sociais", ao mesmo tempo em que traça o percurso que desencadeará no reconhecimento, por parte da Constituição Federal de 1988, às denominadas comunidades "remanescentes de quilombos". Segundo a autora, essas comunidades passaram a representar uma força social significativa no campo brasileiro, cobrindo o que até pouco tempo era nomeado de comunidades negras rurais ou terras de preto, que pode incluir até mesmo os bairros no entorno dos terreiros de candomblé. Essas comunidades reivindicam, principalmente, a regularização de territórios sociais tradicionalmente ocupados tendo origem desde o período da escravidão, como já nos disse Arruti (2006).

No que tange à área educacional, a pesquisadora apresenta dados relevantes para compreensão das condições em que se encontram as escolas e o processo de ensino nas comunidades quilombolas em nosso país. Dentro desse panorama preocupante, a autora faz um recorte dos aspectos educacionais das comunidades quilombolas e das políticas de educação que foram se constituindo nos últimos anos no estado da Bahia. 
Maroun e Arruti (2011), apresentam pesquisa que teve por objetivo tornar compreensível a demanda por uma escola diferenciada, na comunidade quilombola Campinho da Independência localizada em Paraty, no estado do Rio de Janeiro. No ano de 2005, quando a comunidade recebeu o Ponto de Cultura Manoel Martins, onde foram implementadas oficinas, como as de capoeira angola, jongo, cerâmica artística, percussão, dentre outras, com foco nas crianças em idade escolar, objetivando trabalhar a autoestima, bem como questões de identidade, a discussão sobre educação começa a ganhar mais fôlego.

\begin{abstract}
Emergem destas oficinas um contraste importante - sentido tanto pelas lideranças quilombolas quanto pelas professoras e direção da escola - com relação ao rendimento comparado das crianças nas oficinas e na escola. Abre-se, então, um espaço de discussão em função de uma suposta monopolização da atenção dos alunos pelas oficinas em detrimento dos conteúdos escolares. Em decorrência do anunciado acima surge a sugestão da AMOC de que o aprendizado proporcionado pelas diferentes atividades desenvolvidas pelo Ponto de Cultura poderia orientar não só novas possibilidades para o currículo e os conteúdos escolares, como poderia servir de plataforma para a elaboração de um modelo pedagógico novo e apropriado às especificidades da comunidade. (MAROUN e ARRUTI, 2011, p. 6).
\end{abstract}

Nessa perspectiva, a discussão se volta para uma reflexão acerca de uma pedagogia quilombola. Segundo Maroun e Arruti (2011), a princípio a Associação dos Moradores dos Campinhos - AMOC, reivindicava levar até a escola o trabalho das oficinas, com o objetivo de tornar os conteúdos escolares mais significativos para os alunos, uma vez que as oficinas eram desenvolvidas com base na cultura, nas tradições e na memória coletiva da comunidade, o que possibilitaria agregar ao currículo escolar elementos do cotidiano da criança, uma contextualização no ensino, incluindo sua perspectiva de luta. No decorrer do processo, a AMOC passa a reconhecer que uma escola quilombola precisa ser construída num coletivo, pensado pela própria comunidade em parceria com a escola. Para Maroun e Arruti,

\footnotetext{
Eles fazem uma crítica à escola local enfatizando que as práticas pedagógicas escolares não deveriam se restringir apenas à criação de atividades esporádicas que mencionem ou que trabalhem a cultura quilombola, mas que façam parte do cotidiano escolar, ou seja, que, de fato, sejam vivenciadas e incorporadas na/pela escola. (MAROUN e ARRUTI, 2011, p.7).
}

Pensando uma educação para além dos muros da escola, a proposta pedagógica da AMOC visa à educação em todos os âmbitos, do espaço escolar à casa de farinha, traçando um ensino significativo, o que vai de encontro à proposta engessada do modelo de escola que o município oferece, que, inclusive, considera a escola desta comunidade como escola rural.

\begin{abstract}
A discussão trazida por nós a partir da AMOC, seja no campo epistemológico e/ou metodológico, implica na necessidade emergencial de reflexões e mudanças em torno da real função social da escola, e, sobretudo, da função da escola no contexto específico quilombola. Em nossa análise, a "escola quilombola" reivindicada por Campinho se pauta fundamentalmente no princípio da alteridade, considerando a escola uma extensão da comunidade, isto é, um projeto político pedagógico comunitário. (MAROUN e ARRUTI, 2011, p.9).
\end{abstract}

Silva (2011) reflete, a partir da Comunidade Quilombola Conceição dos Crioulos, localizada em Pernambuco, como identidade, territorialidade e educação se apresentam de forma imbricada e, nesse sentido, a vida das pessoas daquela comunidade tem se constituído em processos pedagógicos, visto que suas construções e aprendizagens se materializaram através de um tecido social e de uma história de luta e saber popular, resistência e cultura. As práticas educativas produzidas por esse coletivo, segundo Silva (2011, p. 8), "não ficam 
restritas ao ensinar a ler e escrever, mas também é levada para o campo da organização coletiva, do saber tradicional, da reconstrução da memória, da comunidade, formando um tecido que poderá ser denominado de identidade quilombola”. No início da década de 90 do século passado, quando esta comunidade se encontrava em luta pela sua afirmação como comunidade quilombola, uma das bandeiras mais forte era o acesso à educação, que deveria se encaminhar de forma diferenciada, de modo a atender aos desejos da comunidade.

\begin{abstract}
É nesse momento que a comunidade começa uma grande corrida: formar as pessoas da própria comunidade, pessoas compromissadas com a educação voltada para o fortalecimento da identidade da comunidade. Ao mesmo tempo em um grande movimento interno na comunidade, construiu-se de forma coletiva uma proposta de educação com um currículo próprio e com referências próprias. Esse movimento passa por ser da comunidade o direito desde escolher o nome da escola ao perfil dos/as educadores/as a atuarem na mesma. Um dos princípios básicos era o compromisso com as lutas da comunidade. (SILVA, 2011, p. 10).
\end{abstract}

A educação, para essa comunidade, é entendida como estratégia para fortalecer as lutas por direitos. "As festas da comunidade, as lutas pelo direito ao território, o papel das mulheres, a importância dos/as idosos, o artesanato, as formas de uso, ocupação e apropriação da terra, o dia-a-dia da comunidade são parte do currículo escolar" (SILVA, 2011, p. 11).

A pesquisa de Miranda (2011) recupera a trajetória da educação escolar quilombola em Minas Gerais, utilizando-se de dados do censo escolar realizado pelo Instituto Nacional de Estudos e Pesquisas Educacionais Anísio Teixeira INEP, além de pesquisas realizadas por outros estudiosos da temática, a partir da realidade deste estado. À época de sua pesquisa Minas Gerais contava com quatrocentas e três comunidades remanescentes de quilombo, das quais cento e dezessete encontravam-se certificadas e apenas uma tinha obtido titularidade, colocando este estado em terceiro lugar nacional em relação ao número de comunidades certificadas. $\mathrm{O}$ atendimento escolar em áreas remanescentes de quilombos sinalizava um total de 140 (cento e quarenta escolas), entre estaduais, municipais e privadas.

\begin{abstract}
No que se refere à situação de funcionamento das escolas, Minas Gerais reproduz os indicadores nacionais. A estrutura física, na maioria das vezes, é bastante precária. Há escolas funcionando ao ar livre, ou em prédios adaptados cedidos por igrejas. É comum que estudantes das comunidades remanescentes de quilombos frequentem escolas em outras comunidades, povoados e sede de municípios, caso que se ampliou no estado após o processo de nucleação de escolas. Esse deslocamento é ainda feito a pé. Sendo que em algumas comunidades a distância em relação à escola ultrapassa vinte quilômetros, percorridos diariamente, num percurso de ida e volta. Nos casos de transporte escolar a condição dos veículos é arriscada, com superlotação, desgastes de lataria, pneus e motores. (MIRANDA, 2011, p. 8).
\end{abstract}

Segundo Miranda (2011), de modo geral, Minas Gerais encontra-se em situação de desvantagem em termos de construção de política educacional voltada às comunidades quilombolas e isso tem se refletido na precariedade de formação de professor e nos indicadores de atendimento escolar e na qualidade da educação ofertada a essas comunidades. Em relação aos professores que atuam nessas comunidades, "reiteradamente, encontram-se referências à desconsideração da singularidade das populações quilombolas pelos/as profissionais da educação que atuam em escolas localizadas nessas áreas" (MIRANDA, 2011, p. 9).

Santos (2012) apresenta resultado de pesquisa, parte de sua tese de doutorado, realizada na comunidade quilombola de Bomba, na região de 
Eldorado e Iporanga, no Vale do Ribeira, no estado de São Paulo, em que buscou refletir que referências históricas e culturais estão presentes no interior desta comunidade e em que medida elas dialogam com as tradições africanas, ocidentais e (ou) ameríndias. Nisso, o objeto da pesquisa, segundo a autora, voltou-se à compreensão de quatro elementos: lúdico, cultura, educação e comunidades quilombolas e, durante sua realização, foi dada atenção aos seguintes aspectos: Como ocorrem as práticas lúdicas nesta comunidade; quem são os brincantes; como são inseridos os jogos e brincadeiras no processo educativo; e de que forma esse processo dialoga com a cultura e história do seu povo.

\begin{abstract}
No desenvolvimento do trabalho, em princípio, os habitantes da comunidade de Bombas negavam a brincadeira, o lúdico. Provavelmente atribuíam-lhe um significado pejorativo, de perda de tempo, malandragem, folga. Afirmavam-se todo o tempo como "gente séria, trabalhadora", negando qualquer estereótipo que contradissesse essa visão. Com a convivência e a realização do estudo de caso, aos poucos essa negação e receio foram esmaecendo e revelando uma grande ludicidade, categorizada em quatro grupos: jogos e brincadeiras, brinquedos, situações lúdicas (divertimentos) e narrativas. Essas categorias foram consideradas em suas dimensões temporais e espaciais (ontem/hoje; lugar dos eventos), bem como a frequência com que ocorrem. Foram registrados quarenta e sete jogos e brincadeiras; trinta e dois brinquedos, instrumentos de lazer; vinte e dois registros de situações lúdicas (divertimentos) e quatro tipos principais de narrativas. Totalizam cento e cinco registros com vários desdobramentos. (SANTOS, 2012, p. 6).
\end{abstract}

Segundo Santos (2012) no que tange ao espaço escolar da comunidade, a ludicidade é representada da seguinte forma:

A escola enquanto instituição também vive momentos e situações lúdicas, de brinquedos e brincadeiras. Mas é com tempo marcado e, costumeiramente, trazendo cantos, contos, causos, brincadeiras e jogos da cidade. Com raras exceções reconhece os saberes aprendidos na, da e com a terra. (SANTOS, 2012, p.14).

Ao analisar os conteúdos didáticos, a autora se depara com o método apostilado, fornecido pela Secretaria de Educação, repleto de conteúdos e estratégias pensados para o ensino urbano. O que de fato representa e promove a cultura para as próximas gerações são as expressões de saberes que estão para além da escola, expressadas pelos costumes e valores que são repassados pela família e pela comunidade.

A pesquisa de campo demonstrou que à medida que o lúdico é considerado como elemento da cultura, há indicativos no interior da comunidade de Bombas que o asseguram como prática constante, independentemente da corrente expressão local "aqui não se brinca”. São jogos, brincadeiras, narrativas, festas, narrativas e situações que compõem o cotidiano ou "momentos marcados", como no caso de algumas comemorações. Demonstram a ludicidade dos sujeitos (adultos, jovens, crianças, homens, mulheres), sua interação, apropriação e aplicação de conhecimentos de outrora e de agora, num movimento constante de criação e recriação, em diálogo com o próprio espaço e com o entorno. [...] A educação na comunidade deriva do convívio com o grupo. Crianças aprendem por observar e participar do cotidiano e não somente pelo discurso dos adultos. Não há um momento para ensinar a elas como preparar o fogão a lenha ou usar o machado, o facão. Vão apreendendo a realidade e significando seus primeiros conhecimentos na relação com os outros, tanto crianças como adultos. [...] A Educação, por sua vez, carece urgentemente olhar para essa realidade e agir. Há que se observar, pensar, construir e praticar novas formas de currículo e política públicas que não sejam exclusiva e autoritariamente urbanos: povos tradicionais, das florestas, dos mangues, das terras secas, assumindo a diversidade e colaborando com as proposições e demandas da Educação e relações étnico-raciais. (SANTOS, 2012, p. 14-16).

Fernandes (2012) apresenta um estudo etnográfico, realizado na comunidade quilombola Boitaraca, localizada em Nilo Peçanha, estado da Bahia, em que buscou compreender como se dava a transição do processo 
educacional da comunidade para a escola da cidade, vivenciado por estudantes, posto que, ao terminarem o ensino fundamental I, esses estudantes precisam continuar os estudos na escola da cidade.

A autora começa demonstrando o processo de educação que ocorre na escola do "quilombo" de Boitaraca, com proposta pedagógica pensada pela professora filha desta comunidade, "que reúne princípios, valores, visão de mundo, modos de sociabilidade, linguagens, os quais valorizam o continuum civilizatório africano-brasileiro, a história oral, a memória, a ancestralidade, as vivências cotidianas" (FERNANDES, 2012, p.1). Segundo Fernandes (2012), a história educacional deste quilombo traz singularidades, possíveis de serem percebidas quando a autora relata:

\begin{abstract}
A abertura da escola do "quilombo", para a apreensão das vivências educativas que compõem a vida das crianças e dos jovens de Boitaraca pressupõe, também, uma visão de mundo que não comporta as cercas de um currículo como grade, nem permite propostas pedagógicas que insistem em reproduzir os saberes europeus, porém a escola de Boitaraca compreende a educação como acesso para diversas leituras, diversas práticas que são as práticas de viver e que geram saber nas comunidades quilombolas. (FERNANDES, 2012, p.1).
\end{abstract}

O currículo da escola de Boitaraca, segundo a autora, visa desconstruir as narrativas hegemônicas de identidade que constituem o currículo oficial, tendo a educação como um espaço de luta contra a educação dominante e, portanto, como lugar de reelaboração identitária e de valorização do legado cultural da comunidade.

Por outro lado, ao terminar o ensino fundamental I e seguir para o ensino fundamental II na escola da cidade, há um choque entre conteúdos, métodos de ensino, uma vez que a escola da cidade aparenta uma proposta curricular baseada nos valores eurocêntricos. Para Fernandes (2012), estas crianças e jovens experimentam o sabor amargo e nocivo do preconceito e da discriminação por serem negros e quilombolas. Essa brusca mudança é relatada por uma estudante:

[...] Queria que na escola contassem um pouco sobre os meus antepassados, e que a professora se sentasse debaixo de uma árvore e contasse nossa história. Tenho saudade da escola da comunidade. Lá o povo todo participa da escola, sentamos no chão, cantamos, meu avô sempre vai lá para contar uma história dos antigos. [Aqui, a professora acho que nem sabe da história da gente]. (FERNANDES, 2012, p.7).

A-ian-madê, frase utilizada como título do artigo da autora, traz a reflexão sobre o vivido-concebido das crianças boitaraquences, que tem o privilégio de aprender o que é ser negro, o que é ser quilombola, bem como a se reconhecer dentro da sua história desde cedo. Contudo, na escola da cidade, os saberes das crianças quilombolas passam despercebidos, uma vez que sua linguagem é etnocêntrica, eurocêntrica e pouco tem contribuído para a construção de uma educação antirracista, como avalia a autora.

Brito (2013), além de recuperar o processo que culminou na aprovação das Diretrizes Curriculares Nacionais para a Educação Quilombola, sobretudo as audiências realizadas em 2011, envolvendo lideranças de comunidades quilombolas, militantes do movimento social negro, pesquisadores e educadores de várias regiões do país e gestores públicos situados em várias esferas de governo, apresenta reflexões interessantes a partir do que determinam as referidas Diretrizes, em torno da relação estabelecida entre "o mundo do trabalho" e a educação escolar quilombola, tendo como referência a Comunidade Quilombola da Vila de Santo Isidoro, município de Berilo, em Minas Gerais. 
Em conformidade com o que determina a Constituição Federal de 1988 e a Lei de Diretrizes e Bases da Educação Nacional (9.394/1996), a Resolução no 8 de 2012, que estabelece as Diretrizes Curriculares Nacionais para a Educação Escolar Quilombola na Educação Básica, reconhece, como parte integrante de seus princípios, "o trabalho como princípio educativo das ações didáticopedagógicas da escola" (Art. $7^{\circ}$, Inciso XVIII), bem como o "direito dos estudantes, dos profissionais da educação e da comunidade de se apropriarem dos conhecimentos tradicionais e das formas de produção das comunidades quilombolas de modo a contribuir para o reconhecimento, valorização e continuidade" (Art. $7^{\circ}$, Inciso XVII). De acordo com o texto da Resolução, o locus privilegiado de manifestação desse princípio encontra-se nas formas de organização e funcionamento do Ensino Médio, na Educação de Jovens e Adultos e na Educação Profissional Técnica de Nível Médio.

Segundo Brito (2013), situada na região do Médio Jequitinhonha, a cidade de Berilo, onde se localiza a Comunidade Quilombola da Vila de Santo Isidoro, enfrenta os desafios postos aos outros municípios que compõem esta região dadas as características "climáticas, ocasionando baixos índices pluviométricos durante o ano, e a concentração da propriedade fundiária, repercutindo em oportunidades ocupacionais limitadas, principalmente para a população jovem" (BRITO, 2013, p.9). Esta realidade impõe a necessidade de migração sazonal da população masculina para áreas de cultivo de café e cana nas regiões CentroOeste e Sudeste do país. "O fluxo migratório é visto pelos mais jovens como única alternativa de sobrevivência, dadas as condições precárias oferecidas para a reprodução da vida através do trabalho na comunidade quilombola" (2013, p. 10), trazendo implicações, inclusive, ao funcionamento da escola na comunidade, posto que muitos jovens se veem obrigados a abandoná-la, durante o período de cultivo da cana e do café. Nesse sentido, segundo Brito,

\begin{abstract}
O texto da Resolução exibe um conjunto de referências que, corroborando princípios consagrados em outros documentos, reafirma o princípio educativo do trabalho, que também se incorpora à concepção da educação escolar quilombola. [...] No entanto, as considerações feitas sobre a dinâmica do mundo do trabalho na Comunidade Quilombola da Vila de Santo Isidoro evidenciam que esse princípio, para que seja capaz de orientar ações em prol do desenvolvimento sustentável do território quilombola, demanda ser confrontado com os desafios postos à reprodução da vida nas comunidades historicamente situadas. (BRITO, 2013, p. 14).
\end{abstract}

Maroun, Oliveira e Carvalho (2013) apresentam duas experiências de educação em comunidades remanescentes de quilombo situadas na região Sul do estado do Rio de Janeiro, nos municípios de Angra dos Reis e Paraty: a Comunidade de Santa Rita do Bracuí e Campinho da Independência, as mesmas comunidades estudadas por Maroun e Arruti (2010 e 2011), como já apresentado. Segundo as autoras, no Campinho da Independência,

O debate sobre uma educação escolar quilombola emerge de um contexto de luta identitária travada em um primeiro momento com a escola ali localizada e, em um segundo momento, com a própria Secretaria Municipal de Educação de Paraty. Uma relação marcada por um histórico de conflitos em torno da demanda por um modelo educacional que contemple e legitime sua cultura local, suas demandas políticas e seus modos de vida. (MAROUN, OLIVEIRA e CARVALHO, 2013, p. 9).

Debate que se intensifica durante a década de 1990, época em que os quilombolas fundaram a Associação de Moradores do Quilombo do Campinho (AMOQC), especialmente com a emergência de lideranças políticas jovens desta Associação, mais "afinadas com os discursos dos movimentos negros e mais disponíveis para participarem das articulações políticas que marcaram o início do movimento quilombola nacional, é que embates com a escola local se 
tornaram ainda mais acentuados" (MAROUN, OLIVEIRA e CARVALHO, 2013, p. 9). A partir de 2005, com a implementação de um Ponto de Cultura, que começa a realizar oficinas na comunidade, o debate vai se tornando mais acirrado. As oficinas realizadas pelo Ponto de Cultura, destinadas às crianças em idade escolar, produzem maior interesse nas crianças do que as aulas realizadas pela escola o que faz com que a comunidade.

\begin{abstract}
Abre-se, então, um espaço de discussão em função de uma suposta monopolização da atenção dos alunos pelas oficinas em detrimento dos conteúdos escolares. O que para a comunidade significava o despertar de um novo e importante momento de valorização dos saberes tradicionais pelas crianças quilombolas, para a escola significava o início de um período de embates com a comunidade. (MAROUN, OLIVEIRA e CARVALHO, 2013, p. 10).
\end{abstract}

Conforme as autoras, se inicialmente as lideranças pensavam na parceria com a escola no intuito de levar a ela suas tradições, histórias, culturas e saberes, as resistências e conflitos que emergiram dos limites que a escola impôs a esta inclusão, fazem com que as lideranças abandonem essa proposta inicial e passem a reivindicar a construção de uma "escola quilombola", posto que, até então, a escola existente nessa comunidade, sob responsabilidade do município de Paraty, estava subordinada à coordenação da Educação Rural deste município. A experiência vivida pela comunidade em sua relação com a escola e com a Secretaria Municipal de Educação provocou nas lideranças o desejo e a decisão política de construir uma escola que estivesse a serviço da comunidade, ou seja, uma escola que fosse de fato do quilombo e não uma escola no quilombo.

A Escola Municipal Áurea Pires da Gama não é classificada pela Secretaria Municipal de Educação de Angra dos Reis como escola quilombola. Contudo,

\begin{abstract}
Mesmo que ainda não haja esse devido reconhecimento por parte da secretaria, há um histórico de diálogo entre escola e comunidade que acompanhou uma longa gestão escolar iniciada ainda na década de 1990 e finalizada no ano de 2005. Após esse período, o diálogo perde a força, sendo retomado atualmente pelo viés de uma nova demanda da comunidade: a entrada do jongo na escola. Desse modo, a principal forma de repensar a escola inserida na comunidade vem sendo representada pelo desejo das lideranças políticas de inserção do jongo no currículo escolar. Toda essa questão teve como aporte principal o fato do jongo ter sido um elemento fortemente apropriado no processo de construção e reafirmação identitária entre crianças e jovens quilombolas de Santa Rita do Bracuí. (MAROUN, OLIVEIRA e CARVALHO, 2013, p. 13).
\end{abstract}

Por fim, a pesquisa de Larchert (2013), realizada na Comunidade Quilombola Fojo, localizada em Itacaré, Bahia, reflete sobre as práticas de resistência e os processos educativos utilizados por essa comunidade. Diferente dos outros trabalhos, a autora se utiliza dos aportes teóricos trazidos pelos estudos pós-coloniais e decoloniais, inspirando-se, sobretudo, nos trabalhos de Boaventura de Souza Santos, Anibal Quijano e Enrique Dussel.

Segundo Larchert (2013) a partir dos processos educativos observados no território identidade do Fojo, foram identificados conhecimentos elaborados nas estratégias do cotidiano dos moradores, conferindo-lhes competências cognitivas, afetivas, sociais e políticas. Os processos educativos e as práticas de resistência que contribuem para a existência desta comunidade, conforme Larchert, estariam relacionados à organização espacial, ao modo como as famílias compartilham esse espaço, à organização espacial das residências, aos saberes sobre o plantio e aos cuidados com a horta da família, além de conhecimentos referentes ao clima, às atividades de pesca e às relações produzidas com os animais domésticos e selvagens que, segundo a autora, "são 
constituintes do sentimento de pertença ao território quilombola do Fojo" (LARCHERT, 2013, p. 11).

Todavia, no que diz respeito à escola, esta é compreendida como um espaço que silencia a história e a identidade desta comunidade. Nisso, segundo a autora,

\begin{abstract}
Durante as inserções na escola e de posse dos conteúdos das entrevistas realizadas com os professores verificamos que a escola nunca inseriu na sua prática educativa as questões inerentes à comunidade quilombola. A escola desconhece os conhecimentos, saberes, processos educativos, lutas, histórias e memórias da comunidade negra rural quilombolas do Fojo, mesmo com os professores e alunos pertencentes à família Santos e Gomes. O currículo escolar representa uma força epistemológica contrária ao movimento dialético da resistência quilombola. (LARCHERT, 2013, p. 13).
\end{abstract}

\title{
Considerações finais
}

Por todo o Brasil, são muitas as dificuldades que as comunidades quilombolas enfrentam, tanto no que diz respeito à demarcação de seus territórios, como ao acesso à saúde, ao trabalho digno e à educação de qualidade, dificuldades resultantes, em grande medida, do modo como tem operado o racismo à brasileira (TELLES, 2003; SCHWARCZ, 2012), que continua estruturando nossas relações sociais e raciais, acentuando desigualdades, sobretudo entre a população negra, na qual os quilombolas estão incluídos.

Vimos, a partir da produção da ANPED, que as pesquisas sobre educação escolar em contexto quilombola são ainda incipientes; todavia, tem havido, nos últimos anos, um aumento crescente dessas pesquisas, como demonstrou Miranda (2016). Cardoso e Arruti (2011), ao fazerem levantamento da produção acadêmica em torno da educação quilombola entre 1990 e 2009, identificaram que as regiões sudeste e nordeste se destacam em termos de produção; dos trabalhos publicados na ANPED, excetuando a pesquisa de Marques (2006), todas as demais foram produzidas em comunidades quilombolas do sudeste e nordeste.

De certo modo, as pesquisas aqui apresentadas permitem afirmar que esta modalidade de educação tem sido construída de forma bastante variada e, por vezes, controversa. Maroun e Arruti (2010, 2011), por exemplo, apresentaram os conflitos, dificuldades e disputas envolvidos na construção das escolas quilombolas no Rio de Janeiro: conflitos entre o modelo de escola rural pensado para as comunidades quilombolas, pelas secretarias de educação, que se chocam com o modelo de escola que os quilombolas pensam e desejam para si. Por outro lado, esses mesmos autores demonstram como essas tensões têm produzido, por parte dos quilombolas, um movimento em terno de uma escola diferenciada e na construção de uma "pedagogia quilombola”. A pesquisa de Miranda (2011) refletiu acerca das condições de precariedade das escolas quilombolas de Minas Gerais, tanto no que diz respeito à construção das políticas de educação voltadas para essas comunidades, quanto no que concerne às políticas de professor e a qualidade da educação ofertada. Silva (2011), por outro lado, tendo como campo de pesquisa a Comunidade Quilombola Conceição dos Crioulos, em Pernambuco, demonstra como a escola tem sido construída a partir de um projeto de comunidade, numa perspectiva diferenciada e, nesse sentido, a escola está a serviço da comunidade. Recuperamos esses exemplos para mostrarmos a variedade de projetos de 
escola que estão a se formar por todo o Brasil, em alguns casos com certo pessimismo, sobretudo por parte dos pesquisadores.

A educação escolar quilombola é um movimento em curso, que precisa ser compreendido de forma cuidadosa e isso implica em atentar para as especificidades que mobilizam cada comunidade na construção de seus projetos de escola ou, como já nos advertiu Miranda (2016), é preciso recusar "a tentação de confrontar as experiências em curso com as prescrições normativas advindas de ideias concebidas fora e acima de situações concretas" (MIRANDA, 2016, p. 78). Por fim, acreditamos, que a educação quilombola e para os quilombolas deve-se constituir na perspectiva da diferença e da especificidade, posto que deverá atender ao plano da diferença constitutiva dos modos de existência dessas comunidades que se apresentam tão diversos no território brasileira e latino-americano.

\section{Bibliografia}

ALMEIDA, A.W. B. de. "Os quilombos e as novas etnias". In: LEITÃO, Sérgio (org.) Direitos Territoriais das Comunidades Negras Rurais. São Paulo: Instituto Socioambiental, 1999.

ALMEIDA, Alfredo Wagner B. de. "Quilombos: sematologia face a novas identidades". In: PVN (Org). Frechal: terra de preto, quilombo reconhecido como reserva extrativista. São Luís: SMDDH/CCN - PVN, 1996.

ALMEIDA, Alfredo Wagner Berno de. Terras de preto no Maranhão: quebrando o mito do isolamento. São Luís: SMDH: CCN-MA: PVN, 2002. (Coleção Negra Cosme, v.3.).

ARÊDA-OSHAI, Cristina Ma. "O ressurgimento de antigas categorias em novos contextos: Quilombos e quilombolas vivendo no presente". Revista da ABPN, v. 8, n. 18, nov./2015 -fev./2016., p.255-279, 2016.

ARRUTI, José Maurício Andion. "A emergência dos "remanescentes": notas para o diálogo entre indígenas e quilombolas". In: Revista Mana 3 (2): pp. 7-38, 1997.

ARRUTI, José Maurício Andion. “Quilombos”. In: SANSONE, LÍVIO; ARAÚJO, Osmundo (Orgs.). Raça: novas perspectivas antropológicas. 2 ed. Salvador: Associação Brasileira de Antropologia/EDUFBA: 2008.

ARRUTI, José Maurício Andion. Mocambo: antropologia e história do processo de formação quilombola. Bauru, SP: EDUSC, 2006.

ARRUTI, José Maurício Andion. "Da "Educação do Campo" à "Educação Quilombola": identidade, conceitos, números, comparações e problemas." Raízes, n. 31, v. 1, jan./jun. p. 164- 179, 2011.

ARRUTI, José Maurício Andion. "Políticas Públicas para quilombos: terra, educação e saúde”. In: PAULA, Marilene de; HERINGER, Rosana. (Orgs.). Caminhos convergentes: Estado e sociedade na superação das desigualdades 
raciais no Brasil. Rio de Janeiro: Fundação Heinrich Boll, ActionAid, p. 75-110, 2009.

BRASIL. Constituição da República Federativa do Brasil de 1988. Brasília (DF).

. Decreto $n^{\circ}$ 4.887, de 20 de novembro de 2003. Brasília (DF).

Resolução CNE/CEB $N^{o}$ 8, de 20 de novembro de 2012. Brasília

(DF).

. Diretrizes Curriculares Nacionais Gerais para a Educação Básica. Brasília: Conselho Nacional de Educação, 2010.

. Resolução $n^{o}$ 7, 14 de dezembro. Conselho Nacional de Educação. Câmara da Educação Básica, 2010.

Conferência Nacional de Educação (CONAE). Documento final. Brasília: MEC, SEA, 2010.

Diretrizes Curriculares Nacionais para a Educação das Relações Étnico-raciais e para o Ensino de História e Cultura Afro-brasileira $e$ Africana. Brasília, DF: MEC, 2004.

BRITO, José Eustáquio. "Do quilombo ao canavial: desafios e perspectivas para a implementação da educação escolar quilombola numa comunidade do médio Jequitinhonha”. Anais da $36^{a}$ Reunião Nacional da ANPEd - 29 de setembro a O2 de outubro de 2013.

CARDOSO, Alainaldo Onofre; ARRUTI, José Maurício Andion. A temática quilombola no banco de teses da capes: mapeamento preliminar. Relatório Lapf/PIBITI, PUC/RJ, 2011.

CARNEIRO, Edison. O Quilombo dos Palmares. Rio de Janeiro: Companhia Nacional, 1988.

CARNEIRO DA CUNHA, Manuela. "Políticas culturais e povos indígenas: uma introdução". In: CARNEIRO DA CUNHA, Manuela; CESARINO, Pedro de Niemeyer (Orgs.). Políticas culturais e povos indígenas. São Paulo: Cultura Acadêmica, 2014.

COSTA, Sandra Soares da; DIAS, Maria Helena Tavares; SANTOS, Zizele Ferreira dos. "Educação escolar quilombola: experiência sobre formação de professores em Mato Grosso (Brasil)”. Revista da ABPN, v. 8, n. 18, nov./2015 fev./2016., p. 90-106, 2016.

DOMINGUES, Petrônio; GOMES, Flávio. "Histórias dos quilombos e memórias dos quilombos no Brasil: Revisitando um diálogo ausente na Lei 10.639/2003”. Revista da ABPN, v. 5, n. 11, jul.- out. p. 05-28, 2013.

FERNANDES, Mille Caroline Rodrigues. "A-ian-madê? Processo educacional de crianças quilombolas na escola da cidade”. Anais da $35^{a}$ Reunião Nacional da ANPEd, 2012. 
FERNANDES, Mille Caroline Rodrigues. MBAÉTARACA: uma experiência de educação de jovens quilombolas no município de Nilo Peçanha/BA. Programa de Pós-Graduação em Educação - Universidade do Estado da Bahia (dissertação de mestrado). Salvador: UNEB, 2013.

FIGUEIREDO, André Videira de. O caminho quilombola: sociologia jurídica do reconhecimento étnico. Curitiba: Appris, 2011.

GOMES, Flávio dos Santos. Mocambos e Quilombos: Uma História do campesinato negro no Brasil. São Paulo: Companhia das Letras, 2015.

GUSMÃO, Neusa Maria Mendes de. "Herança quilombo: negros, terras e direitos". In: BACELAR, Jeferson; CAROSO, Carlos (Orgs.). Brasil: um país de negros? 2 ed. Rio de Janeiro: Pallas; Salvador, BA: CEAO, 2007.

GUSMÃO, Neusa Maria Mendes de. "Herança quilombola: negros, terras e direitos". In: MOURA, Clóvis (Org.). Os quilombos na dinâmica social do Brasil. Maceió: EDUFAL, 2001.

GUSMÃO, Neusa Maria Mendes de. "Antropologia e educação: a conflitualidade em questão". In: Os filhos de África em Portugal: Antropologia, multiculturalidade e educação. Lisboa: ICS, 2004.

GUSMÃO, Neusa Maria Mendes de. "Antropologia e educação: origens de um diálogo”. Cadernos Cedes, Campinas, v. 18, n. 43, p. 26-37, 1997.

GUSMÃO, Neusa Maria Mendes de; SOUZA, Márcia Lúcia Anacleto de. "Educação quilombola: entre saberes e lutas". In: DAUSTER, Tania; TOSTA, Sandra Pereira; ROCHA, Gilmar (Orgs.). Etnografia e educação: culturas escolares, formação e sociabilidades infantis e juvenis. Rio de Janeiro: Lamparina, 2012.

LARCHERT, Jeanes Martins. "Epistemologia da resistência quilombola em diálogo com o currículo escolar”. Anais da $36^{a}$ Reunião Nacional da ANPEd 29 de setembro a 02 de outubro de 2013.

MAROUN, Kalyla; ARRUTI, Jose Mauricio Paiva Andion. “A ressignificação do jongo e sua relação com a educação em duas comunidades quilombolas do Rio de Janeiro: Bracuhy e Campinho da Independência”. Anais da $33^{a}$ Reunião Nacional da ANPEd, 2010.

MAROUN, Kalyla. ARRUTI, Jose Mauricio Paiva Andion. "Educação quilombola em debate: A escola em Campinho da Independência (RJ) e a proposta de uma pedagogia quilombola". Anais da $34^{a}$ Reunião Nacional da ANPEd, 2011.

MAROUN, Kalyla; OLIVEIRA, Suely Noronha de; CARVALHO, Edileia. "Educação escolar quilombola: diálogos e interfaces entre experiências locais e a institucionalização de uma nova modalidade de educação no Brasil”. Anais da $36^{a}$ Reunião Nacional da ANPEd - 29 de setembro a 02 de outubro, GoiâniaGO, 2013. 
MARQUES, Eugenia Portela de Siqueira. "A identidade negra e o currículo escolar: Um estudo comparativo entre uma escola de periferia e uma escola de remanescentes de quilombos". Anais da $29^{a}$ Reunião Nacional da ANPEd, 2006.

MACEDO, Dinalva de Jesus Santana. Educação em Comunidades Quilombolas do Território de Identidade do Velho Chico/BA: indagações acerca do diálogo entre as escolas e as comunidades locais. Programa de Pós-Graduação em Educação - Universidade do Estado da Bahia (tese de doutorado). Salvador: $U N E B, 2015$.

MIRANDA, Shirley Aparecida de. "Dilemas do reconhecimento: a escola quilombola que "vi de perto"”. Revista da $A B P N$, v. 8, n. 18, nov./2015 fev./2016., p.68-89, 2016.

MIRANDA, Shirley Aparecida de. "Educação escolar quilombola em Minas Gerais: entre ausências e emergências". Anais da $34^{a}$ Reunião Nacional da ANPEd, 2011.

MOURA, Clóvis. Rebeliões da senzala: quilombos, insurreições, guerrilhas. 3 . ed. São Paulo: Livraria Editora Ciências Humanas, 1981.

MOURA, Clóvis (Org.). Os quilombos na dinâmica social do Brasil. Maceió: EDUFAL, 2001.

NASCIMENTO, Abdias. O quilombismo. Petrópolis: Vozes, 1980.

NASCIMENTO, Beatriz. "O conceito de quilombo e a resistência afrobrasileira”. In: NASCIMENTO, Elisa Larkin (Org.). Cultura em movimento: matrizes africanas e ativismo negro no Brasil. São Paulo: Selo Negro, 2008.

O'DWYER, Eliane Cantarino. “"Remanescentes de Quilombos” do Rio Erepecuru: o lugar da memória na construção da própria história e de sua identidade étnica". In: BACELAR, Jeferson; CAROSO, Carlos (Orgs.). Brasil: um país de negros? 2 ed. Rio de Janeiro: Pallas; Salvador, BA: CEAO, 2007.

O'DWYER, Eliane Cantarino. "Relatório Antropológico sobre terras de quilombo: balanço e prospectivas de uma antropologia em ação”. In: O'DWYER, Eliane Cantarino (org.). O fazer antropológico e o reconhecimento de direitos constitucionais: o caso das terras de quilombo no Estado do Rio de Janeiro. Rio de Janeiro: E-papers, 2012.

O'DWYER, Eliane Cantarino. "Nota introdutória: construções identitárias: nada vem do nada”. In: O'DWYER, Eliane Cantarino (org.). O processo identitário e a produção da etnicidade. Rio de Janeiro: E-papers, 2013.

O'DWYER, Eliane Cantarino. Terra de quilombos. Rio de Janeiro, Associação Brasileira de Antropologia,1995.

OLIVEIRA, Osvaldo Martins de (Org.). Direitos quilombolas \& dever de Estado em 25 anos da Constituição Federal de 1988. Rio de Janeiro: Associação Brasileira de Antropologia, 2016. 
OLIVEIRA, Rita de Cássia Magalhães de. Tessituras das diversidades: cultura(s) no cotidiano da escola de um território rural-quilombola. Programa de Pós-Graduação em Educação - Universidade do Estado da Bahia (dissertação de mestrado). Salvador: UNEB, 2014.

OLIVEIRA, Suely Noronha de. "Da educação do campo à educação quilombola: Esboço de um percurso". Anais da 34 ${ }^{a}$ Reunião Nacional da ANPEd, 2011.

ONOFRE, Joelson Alves. A lei 10.639/o3 e seus desdobramentos em uma escola quilombola. Programa de Pós-Graduação em Educação - Universidade Federal da Bahia (dissertação de mestrado), Salvador: UFBA, 2014.

PARÉ, Marilene Leal; OLIVEIRA, Luana Paré de; VELLOSO, Alessandra D’Aqui. "A educação para quilombolas: experiências de São Miguel dos Pretos em Restinga Seca (RS) e da comunidade Kalunga do Engenho II (GO)”. Cadernos Cedes, Campinas, vol. 27, n. 72, maio/ago p. 215-232, 2007.

PEREZ, Carolina dos Santos Bezerra. "O ensinar e o aprender do jongo em comunidades quilombolas: a maestria dos jongueiros Cumba”. Anais da $34^{a}$ Reunião Nacional da ANPEd, 2011.

PURIFICAÇÃO, Josemar Oliveira. Educação Escolar Quilombola: um estudo sobre os aspectos difundidos no Quilombo Rio das Rãs. Programa de PósGraduação em Educação - Universidade do Estado da Bahia (dissertação de mestrado). Salvador: UNEB, 2015.

RAMOS, Rosamaria Sarti de Lima. "A questão da escolaridade nas comunidades quilombolas do Vale do Ribeira”. Anais do IX encontro de pesquisa em educação da região sudeste, São Paulo: UFSCAR, 2009.

RATTS, Alecsandro J. P. "(Re)conhecer quilombos no território brasileiro: estudos e mobilizações”. In: FONSECA, Maria Nazareth Soares (Orgs). Brasil afro-brasileiro. Belo Horizonte: Autêntica, 2000.

REIS, Maria Clareth Gonçalves. Escola e contexto social: um estudo de processos de construção da identidade racial numa comunidade remanescente de quilombo. Programa de Pós-Graduação em Educação (dissertação de mestrado), Juiz de Fora: FE/UFJF, 2003.

REIS, João José; GOMES, Flávio dos Santos (Orgs.). Liberdade por um fio: História dos quilombos no Brasil. São Paulo: Companhia das Letras, 1996.

ROCHA, Gilmar; TOSTA, Sandra Pereira. Antropologia e educação. Belo Horizonte: Autêntica, 2009.

SAHLINS, Marshall. "La pensée bourgeoise: a sociedade ocidental como cultura (1976)”. In: SAHLINS, Marshall. Cultura na prática. Rio de Janeiro: UFRJ, 2004 .

SANTOS, Maria Walburga dos. Saberes da terra: o lúdico em Bombas, uma comunidade quilombola (estudo de caso etnográfico). Programa de PósGraduação em Educação (tese de doutorado), FE/USP, 2010. 
SANTOS, Maria Walburga dos. "O lúdico em uma comunidade quilombola: Inspirações para a educação das relações étnico-raciais”. Anais da $35^{a}$ Reunião Nacional da ANPEd, 2012.

SANTOS, Tatiane Campos dos. Relações entre território e educação na comunidade quilombola Vila de Santo Isidoro, Berilo, MG. Dissertação (Mestrado em Geografia). Universidade Federal de Minas Gerais, Belo Horizonte, MG, 2015.

SCHWARCZ, Lilia Moritz. Nem preto nem branco, muito pelo contrário: cor e raça na sociabilidade brasileira. São Paulo: Claro Enigma, 2012.

SILVA, Givânia maria da. "Identidade, territorialidade e educação na comunidade quilombola de conceição das crioulas”. Anais da $34^{a}$ Reunião Nacional da ANPEd, 2011.

SILVA, Kleide Iraci Marques. A Construção da Identidade Quilombola na Percepção dos Jovens de Araçá/Cariacá, Bom Jesus da Lapa- Bahia. Programa de Pós-Graduação em Educação - Universidade do Estado da Bahia (dissertação de mestrado). Salvador: UNEB, 2014.

SILVA, Paulo Sérgio da. Contornos pedagógicos de uma educação escolar quilombola. Programa de Pós-Graduação em Educação (tese de doutorado), Porto Alegre: UFRS, 2013.

SOUZA, Márcia Lúcia Anacleto de. Educação e identidade quilombola em Brotas. Programa de Pós-Graduação em Educação (dissertação de mestrado), Campinas: UNICAMP, 2009.

TELLES, Edward. Racismo à brasileira: Uma nova perspectiva sociológica. Rio de Janeiro: Relume Dumara- Funcação Ford, 2003.

TOSTA, Sandra Pereira; ROCHA, Gilmar (Org.). Diálogos sem fronteira: história, etnografia e educação em culturas Ibero-Americanas. Belo Horizonte: Autêntica, 2014.

TRINDADE, Creusa Barbosa dos Santos; ARAGÃO, Rosália Maria Ribeiro. "Educação escolar quilombola: interfaces, travessias e fronteiras da prática pedagógica”. Revista da $A B P N$, v. 8, n. 18, nov./2015 -fev./2016., p. 280-295, 2016.

\section{Recebido em 20/11/2016. Aprovado em 10/12/2016.}

